\title{
CAN WE COUNTERACT THE SEPTEMBER 11 CONSPIRACY MEME? AN ARGUMENT FOR USING THE DOCUMENTARY 9/11 IN THE AMERICAN SURVEY
}

\author{
Jessamyn Neuhaus \\ SUNY Plattsburgh
}

\section{Introduction $^{1}$}

"Our own government blew up the Twin Towers for some nefarious purpose? Ridiculous ideas espoused by a lunatic fringe." That is the typical reaction of other history teachers when I tell them that I am researching how to address $9 / 11$ conspiracy theories in my classes. But studies consistently show that a majority of students are statistically likely to believe some aspect of $9 / 11$ conspiracy theories. A 2006 national poll found that over sixty percent of Americans age 18 to 29 believed either that the U.S. government acted to make $9 / 11$ happen or passively let it happen to further its own political ends. Research in 2011 confirmed that a large percentage of 9/11 "truthers" are students and young people. ${ }^{2}$ Although most of us teaching U.S. history today would rather not even acknowledge its existence, let alone address it in our classrooms, 9/11 conspiracism is having an influence on our students. We must begin to think about how we might contend with it, and with the online world where "memes" like September 11 conspiracy theories influence and impact students' way of thinking and learning.

In this article, I argue that 9/11 conspiracy theories - how they are created, accessed, and disseminated - are liable to be uniquely compelling for members of the iGeneration, and that our standard history-teacher toolkit might be largely ineffectual when it comes to counteracting it, particularly at the survey level. I discuss how I have attempted to address this issue by using the Naudet brothers' documentary $9 / 11$ in class, and consider how certain aspects of the documentary that rightly trouble scholars are, paradoxically, the very qualities that help advance student learning and could perhaps "inoculate" some students against 9/11 conspiracy theories. I offer no one-size-fits-all

\footnotetext{
${ }^{1}$ My thanks to Dr. Michael Wolfe and all the organizers and participants of the 2011 conference, "Making Meaning of 9/11 Ten Years After: Local Impact, Global Implications" at St. John's University, where I first presented this work.
}

${ }^{2}$ Kathryn S. Olmstead, Real Enemies: Conspiracy Theories and American Democracy, World War I to 9/II (New York: Oxford University Press, 2009), 229; Nancy Jo Sales, "Click Here for Conspiracy," Vanity Fair, August 2006, http://www.vanityfair.com/ontheweb/features/2006/08/loosechange200608 (accessed June 16, 2014); James Bartlett and Carl Miller, "A Bestiary of the 9/11 Truth Movement: Notes from the Front Line," Skeptical Inquirer 35 (July/August 2011), 43. 
solution, only possibilities for your own teaching. ${ }^{3}$ By raising these possibilities, I seek to begin a conversation about how history teachers might address this troubling issue. ${ }^{4}$

\title{
Conspiracy 2.0: The 9/11 Meme
}

In some ways the emergence of $9 / 11$ conspiracy theories is simply another chapter in the long history of what Richard Hofstadter famously termed "the paranoid style of American politics." ${ }^{\circ 5}$ Conspiracy theories have long circulated among Americans of all racial, class, and economic backgrounds, and political affiliations from far Right to far Left, and have only multiplied since the 1960s and 1970s in the wake of revelations about covert and illegal activities of the U.S. government. Historian Katherine Olmstead points out that when Americans "charge that the government has plotted, lied, and covered up, they're often right.". From Watergate and Iran-Contra to Tuskegee and the secret Nevada Cold War nuclear test sites, examples of real lies and coverups offer Americans considerable fuel for conspiracism suspicions.

Like other popular conspiracy theories, $9 / 11$ conspiracism taps into an American emphasis on individual empowerment. As journalist Lev Grossman writes about Loose Change, the much viewed and downloaded web-based video (at least ten million viewers by one researcher's 2009 count) that posits a 9/11 conspiracy:

\footnotetext{
${ }^{3}$ Because teaching and learning are what David Daniel describes as "messy interactions" in specific, localized contexts shaped by individualized factors, I believe that even the best scholarship on teaching can only offer possibilities, discussion, and reflection, not some set formula for success. David Daniel, "Neuroscience, Learning Science and Other Claims for the Classroom: What Sort of Evidence Makes it Pedagogy?" Lilly International Conference on College and University Teaching and Learning Methods, Bethesda, MD, May 29, 2014.
}

\begin{abstract}
${ }^{4}$ As one reviewer of this article stated regarding $9 / 11$ conspiracy: "I am not sure it is good sense to give this distorted point of view the credibility of a rebuttal, instead of contempt." Given this widespread (and entirely understandable) attitude, it is no surprise that the current scholarship on teaching September 11 does not address the rise of a 9/11 conspiracy. See for example Jacqueline Brady, "Cultivating Critical Eyes: Teaching the Lessons of 9/11 Through Video and Cinema," Cinema Journal 43 (2004), 96-99; Leo Casey, "Teaching the Lessons of 9/11," Dissent no. 1 (2003), 50-58; Jeffrey Merrick, "July 14 and September 11: Historical Method and Pedagogical Method," The History Teacher 39 (2006), 197-214; Amy Scullane, "Student Reactions to 9/11, Then and Now," Journal of Education 188 (2007), 55-71.
\end{abstract}

${ }^{5}$ Richard Hofstadter, "The Paranoid Style in American Politics," in The Fear of Conspiracy: Images of Un-American Subversion from the Revolution to the Present, ed. David Brion Davis (Ithaca: Cornell University Press, 1971).

${ }^{6}$ Olmstead, Real Enemies, 174, 3. See also Kate Zernike, "The Persistence of Conspiracy Theories," New York Times, April 30, 2011, http://www.nytimes.com/2011/05/01/weekinreview/01 conspiracy.html (accessed June 15, 2014). 


\begin{abstract}
Loose Change appeals to the viewer's common sense: it tells you to forget the official explanations and the expert testimony, and trust your eyes and brain instead. It implies that the world can be grasped by laymen without any help or interference from the talking heads. Watching Loose Change you feel as if you are participating in the great American tradition of selfreliance and nonconformist, antiauthoritarian dissent. You're fighting the power. ${ }^{7}$
\end{abstract}

Conspiracy theories create a pleasurable awareness of knowing something that others do not know. 9/11 "truthers," as they call themselves, assert that they have accessed "the truth" when they question the official September 11 narrative in a variety of ways, from doubting that a plane crash could result in the complete collapse of the Twin Towers to skepticism about the failure of U.S. military defenses. ${ }^{8}$

Though echoing earlier popular conspiracies, the explosion of $9 / 11$ conspiracism also signals a seismic change in how Americans conjecture, circulate, and are exposed to conspiracy theories. In a word, that change is the Internet. The simplest transformation wrought by the Internet is the ability of conspiracy theorists to locate each other and to share ideas, writings, and other materials far more rapidly and easily. But communications scholar Charles Soukup argues that more than simply a medium to spread a message, the digital online world creates a hypertextual media environment that is peculiarly conductive to fostering conspiracy theories. ${ }^{9}$ He points out that two

${ }^{7}$ Lev Gossman, "Why The 9/11 Conspiracies Won't Go Away," Time, September 11, 2006, 46-48; Olmstead, Real Enemies, 1.

\footnotetext{
${ }^{8}$ For descriptions of the various 9/11 conspiracy theories, see Christina Asquith, "Conspiracies Continue to Abound Surrounding 9/11," Diverse: Issues in Higher Education 23 (2006), 12-13; Christopher Hayes, "9/11: The Roots of Paranoia," The Nation, December 25, 2006, 11-14; Craig Morris, "September 11," 650, in Peter Knight, ed., Conspiracy Theories in American History: An Encyclopedia (Santa Barbara: ABC Clio, 2003); Christian Schlegel, The Rhetoric of Conspiracy: Theories of September 11 (Germany: Druck and Bindung, 2003); Scott Sommers, "Who Still Believes in 9/11 Conspiracies?" Skeptic 16 (2011), 13-16; Will Sullivan, "9/11 From a Grassy Knoll," U.S. News and World Report, September 3, 2006, http://www.usnews.com/usnews/news/articles/060903/11 conspiracy_2.htm (accessed July 7, 2011). On the Scholars for 9/11 Truth, an organization of professional academics who believe the U.S. government played a nefarious role in the $9 / 11$ attacks, see John Gravois, "Professors or Paranoia?" Chronicle of Higher Education, June 23, 2006, A10-13. On the current climate of conspiracy in the U.S., see Jonathan Kay, Among the Truthers: A Journey Through America's Growing Conspiracist Underground (New York: Harper, 2011). For a psychological study of 9/11 conspiracy adherents in Great Britain, see Viren Swami, Tomas ChamorroPremuzic, and Adrian Furnham, "Unanswered Questions: A Preliminary Investigation of Personality and Individual Difference Predictors of 9/11 Conspiracist Beliefs," Applied Cognitive Psychology 24 (2010), 749-761.
}

${ }^{9}$ Charles Soukup, "9/11 Conspiracy Theories on the World Wide Web: Digital Rhetoric and Alternative Epistemology," Journal of Literacy and Technology 9 (2008), 17-18. 
of the first and most widely circulated $9 / 11$ conspiracy texts-Loose Change and the website 911 Truth.org - constitute a "thoroughly multi-media discourse involving a wide array of images, video, sound, and hypertext" and "via the open-endedness of hypertext, 9/11Truth.org encourages the web browser to serve as the subject/agent piecing together meaning from the encyclopedic reservoir of information." $\mathrm{He}$ concludes that "rather than undermining its effectiveness ... it is the fragmented and open-ended nature of these Websites that (at least partly) account for their tremendous popularity and influence." 10 Soukup's analysis also holds true for the hundreds of other blogs, posts, and YouTube videos claiming a 9/11 government coverup.

It is the very nature of these texts - a mix of images, music, links, documents, and questions, rather than a coherent narrative and traditional argument- that makes them an effective means for articulating and spreading conspiracy theories. Hypertexts, with their innumerable links, layers, and pathways, are incredibly good at fostering the individual rewards of "truth-seeking" inherent to all conspiracy theories. They are part of the web-based cut-and-paste media world where traditional standards of citation and argumentation do not apply. Most academics, who have been trained to assess sources and weigh arguments, and who must adhere to these scholarly standards in order to participate in the profession, reject such an approach. But these texts, and how they are spread and accessed, are highly representative of the online and networked world in which iGen lives.

\section{"Someone had posted a picture": 9/11 Conspiracy, the iGen Online, and History Education}

Delineated as Americans born after 1990, iGen is defined first and foremost by the enormous role communications technology plays in their daily lives. ${ }^{11}$ The Internet has always been their primary means of interacting with information of any kind. If $9 / 11$ conspiracy theories are postulated and circulated principally via online materials and hypertext, and via what sociologist Ted Goertzel terms "the conspiracy meme," then iGen students are particularly susceptible. ${ }^{12}$ Our students are not simply users or viewers of online material: The Internet and their use of social media fundamentally shape their knowledge and understanding of the world. ${ }^{13}$ Dedicated teachers are finding

\footnotetext{
${ }^{10}$ Tbid., 10, 12, 14.

${ }^{11}$ Larry D. Rosen, "Teaching the iGeneration," Educational Leadership 68 (February 2011), 12.

${ }^{12}$ Ted Goertzel, "The Conspiracy Meme," Skeptical Inquirer 35 (January/February 2011), 28.

${ }^{13}$ One study found that consumers of traditional media such as newspapers were statistically less likely to believe any $9 / 11$ conspiracy theory. See Carl Stemple, Thomas Hargrove, and Guiḍo Stemple III, "Media Use, Social Structure, and Belief in 9/11 Conspiracy Theories," Journalism and Mass
} 
ways to incorporate students' technology-influenced thinking into high school and college classrooms. ${ }^{14}$ But as most educators know, the so-called "digital natives" are not especially adept at sorting and assessing the information they access online; they often lack the critical thinking skills necessary to review and question sources and arguments carefully. ${ }^{15}$ It is no wonder that the hodgepodge of images, de-contextualized facts, and unsupported claims that comprise 9/11 conspiracy texts online appear to be convincing millions of teenagers and young adults that the U.S. government either deliberately caused or deliberately allowed the events of $9 / 11$ to happen. ${ }^{16}$ The very nature of these texts is fundamentally different than standard print or video media. They are a new type of media institution that is viewed by the iGen not as static, but rather interactive, "live," and compelling in a way that standard documentaries (let alone textbooks) are not. ${ }^{17}$

In a 2006 interview, Dylan Avery, the creator of Loose Change, vividly articulated the power and appeal of the online 9/11 conspiracy meme:

I started researching $9 / 11$ and I found an article on the World Trade Center - someone had posted a picture of a controlled demolition and then a picture of the World Trade Center collapsing. And I was like, Wow, O.K. And then you find one article and that article links to 10 others, and before you know it you're up until six in the morning. It's crazy, the information takes over. ${ }^{18}$

Communications Quarterly 84 (2007), 353-372.

${ }^{14}$ See for examples, Larry D. Rosen, Rewired: Understanding the iGeneration and the Way They Learn (New York: Palgrave Macmillan, 2010), with Rosie Sheldrake and Neal Watkin, "Teaching the iGeneration: What Possibilities Exist In and Beyond the History Classroom?" Teaching History 150 (March 2013), 30-35.

\footnotetext{
${ }^{15}$ See for example, Anoush Margaryan, Allison Littlejohn, and Gabrielle Vojt, "Are Digital Natives a Myth or Reality? University Students' Use of Digital Technologies," Computers \& Education 56 (February 2011), 429-440.
}

${ }^{16}$ For an overview of online conspiracy sites and materials, see James Broderick and Darren Miller, Web of Conspiracy: A Guide to Conspiracy Theory Sites on the Internet (New Jersey: CyberAge Books, 2008).

\footnotetext{
${ }^{17}$ Peter Ole Pedersen, "The Never-ending Disaster: 9/11 Conspiracy Theory and the Integration of Activist Documentary on Video Websites," Acta Universitatis Sapientia 6 (203), 49.
}

${ }^{18}$ Sales, "Click Here for Conspiracy." 
Avery's obvious pleasure in clicking through the web's infinite number of links and pathways ("you're up until six in the morning") reveals the signifying and meaningmaking process via hypertexts that so amplifies the core appeal of conspiracy theories generally and 9/1 1 conspiracies specifically. Moreover, Avery's lack of concern about the creator's qualifications or even the basic credibility of the "information" that initially caused him to question mainstream $9 / 11$ narratives - "someone had posted a picture"-is unmistakably the hallmark of iGen online. For many of them living in a digital world, authorship simply does not matter. They have a source of virtually unlimited information at their fingertips, but generally speaking, they arrive at college unable to critically examine, assess, or interrogate that information. ${ }^{19}$

In the same interview, Avery expressed sentiments typical of any conspiracist: "You can't believe anything someone tells you just because they told you to. Especially your government, and especially your media - the two institutions that are put there to control you. ${ }^{920}$ Avery echoes countless conspiracy theorists, but there is a critical difference: Unlike any previous era, the digital tools at Avery's disposal allowed him to create an engaging, visually-based document encouraging others to question mainstream 9/11 narratives, and to make it accessible to innumerable viewers. Social science researchers Jamie Bartlett and Carl Miller found that a large portion of 9/11 "truther" online content is created by youth whose "sense of justice and idealism is rudely confronted by a world of state espionage, links between big business and government, and lies over weapons of mass destruction (WMDs)" and whose skilled use of digital technology "produces much of the cool countercultural content of the movement" such as a YouTube video of the Towers falling "set to the electronic dubstep track "Could This Be Real (Joker Remix)."'21 In fact, 9/11 conspiracy offers an explanation for the attacks that any youthful pop culture consumer will find familiar. One journalist described this by referencing Dan Brown, author of an enormously popular 2003 conspiracy thriller The Da Vinci Code: "As a narrative, the official story that the government-echoed by the media-is trying to sell shows an almost embarrassing lack of novelistic flair, whereas the story the conspiracy theorists tell about what happened on Sept. 11 is positively Dan Brownesque in its rich, exciting, complexity."22

\footnotetext{
${ }^{19}$ See for example Eva Brumberger, "Visual Literacy and the Digital Native: An Examination of the Millennial Learner," Journal of Visual Literacy 30 (2011), 19-27; Caroline Geck, "The Generation Z Connection: Teaching Information Literacy to the Newest Net Generation," Teacher Librarian 33 (February 2006), 19-23.

${ }^{20}$ Sales, "Click Here for Conspiracy."

${ }^{21}$ Bartlett and Miller, "A Bestiary of the 9/11 Truth Movement: Notes from the Front Line," 43.

${ }^{22}$ Gosman, "Why The 9/11 Conspiracies Won't Go Away," 46-48.
} 
There are numerous ways that history teachers in upper-level classes and seminars could respond productively to the spread of $9 / 11$ conspiracism among iGen. Any history methodology class, with its emphasis on assessing primary and secondary sources, making sound arguments, and assessing others' assertions about the past, could address the reliability of a text such as Loose Change. A course on the long history of conspiracy theories in the United States - a class that explores the basic appeal of such theories as well as the ways revelations about our government's real obfuscations contribute to them-could effectively help students understand the emergence of $9 / 11$ conspiracies. Small discussion groups would allow the teacher to fruitfully draw out students' previous exposure to 9/11 conspiracy ideas. Any such discussion could deteriorate easily into a futile standoff between student and teacher: "But you can't tell me for sure that it's not true." But in a small class, teachers could more easily implement discussion leadership techniques and strategies for ensuring that students move past simple reaction and opinion and towards real discussion-based learning. ${ }^{23}$

I believe that most students with a major or minor in history taking upper-level history classes, with the help of careful course planning on our part, should be able and willing to interrogate $9 / 11$ conspiracy thinking as part of their training in the discipline. But for those of us teaching standard general education classes, limited class time and large sections of non-history majors severely hamper our ability to construct a careful, step-by-step path for students to examine the online world of $9 / 11$ conspiracism critically. Ideally, we give students the skills and resources to decode media and empower them to assume responsibility for their own learning in the classroom and out in the world as consumers and citizens. But without providing them with detailed historical contextualization and extensive training on assessing online sources and other types of evidence - which often is just not possible within the limits of our survey classes especially-many of our students risk uncritical exposure to $9 / 11$ conspiracy theories.

We must also be aware of the difficulty of persuading those few students who arrive in our classroom absolutely convinced of 9/11 conspiracy to think otherwise. Goertzel explains that committed conspiracists utilize "selective skepticism," that is, they "are doubtful about information from the government or other sources they consider suspect. But, without criticism, believers accept any source that supports their preconceived views." ${ }^{24}$ Today's media and social networking environment, "where you never have to confront an idea you don't like," ensures that conspiracists have unlimited

\footnotetext{
${ }^{23}$ See for example John Henning, The Art of Discussion-Based Teaching: Opening Up Conversation in the Classroom (New York: Routledge, 2008); Jeff Zwiers and Marie Crawford, Academic Conversations: Classroom Talk That Fosters Critical Thinking and Content Understanding (Portland, ME: Stenhouse Publishers, 2011).
}

${ }^{24}$ As quoted and summarized in Bruce Bower, "Tracing the Inner World of Suspicion," Science News, June 20, 2009, 11. See also Olmstead, Real Enemies, 11. 
access to materials that only reinforce their beliefs. ${ }^{25}$ Even the best history teachers and professors will face considerable obstacles trying to convince a dedicated "truther" to rethink his or her selective skepticism about September 11 because our privileged position as culturally sanctioned arbiters of knowledge automatically renders us a suspect source. As Soukup writes,

For those concerned about the proliferation of conspiracy theories, the emergence of digital conspiracy theorizing suggests that the historical methods of delegitimizing conspiracy theories will likely prove ineffective. Suggesting that the "narrative" lacks fidelity or that the "arguments" lack logical warrants will simply not do. As hypertextual open-ended bricolage, these "theories" are neither fundamentally narratives nor arguments. ${ }^{26}$

In other words, any effort we make to methodically critique or to help our students methodically critique the $9 / 11$ conspiracy meme must contend not only with the selective skepticism of conspiracists but also the complex power of an online hypertext spread via interactivity.

History teachers need to consider how the $9 / 11$ conspiracy meme is spreading among iGen students and to acknowledge that traditional strategies for teaching history might not be very effective in counteracting the meme. We need to discuss more openly how many of us, belonging to an earlier generation - and, moreover, extensively trained in critical reading and thinking-are just not as tuned into the way that living online is shaping our students' thinking as we need to be. We need to reflect on this problem and how it might impact our ability to contend with $9 / 11$ conspiracism. We need to ask: What can we do in our classes to try to ensure that students leave with a solid understanding of the historical reality of September 11 ?

\section{Too Hollywood? The Pedagogical Possibilities of $9 / 11$ in the Survey Class}

If 9/11 conspiracy theories tell a gripping "Dan Brownesque" story, perhaps we need to tell a good story as well. The documentary $9 / 11$, created by French filmmaking brothers Jules and Gideon Naudet, tells a gripping story in a dramatically stylized way that I believe could help inoculate students against 9/11 conspiracy theories. ${ }^{27}$ In 2001,

\footnotetext{
${ }^{25}$ Zernike, "The Persistence of Conspiracy Theories."

${ }^{26}$ Soukup, "9/11 Conspiracy Theories on the World Wide Web," 19.

${ }^{27}$ 9/11: The Filmmakers' Commemorative DVD Edition, DVD, directed by Jules Naudet, Gideon Naudet, and James Hanlon (Hollywood: Paramount Studios Home Video, 2002).
} 
the Naudets set out to make an inspiring true-life film about New York City firefighters. ${ }^{28}$ They followed Tony Benetatos, a young (21 years old), highly idealistic firefighter just beginning his career with the NYFD, throughout his training and his probationary period in Firehouse Engine 7, Ladder 1, the closest firehouse to the Twin Towers. On September 11, 2001, the Naudets found themselves unexpectedly documenting the events of that day alongside these first responders.

The resulting film features many eyewitness scenes from Ground Zero on September 11 and the rescue efforts in the following days. Some of the most dramatic footage was captured by the less experienced camerawork of the younger brother Jules, who had been practicing filming with the Battalion Chief during a routine investigation of gas odor on the street when the first plane hit Tower One. His shot of the plane overhead is the only footage of the first plane crash. Jules then accompanied the firemen into the Tower, filming the initial attempts to rescue those in the building and, eventually, its collapse as he and others fled. Gideon meanwhile filmed Tony, who was left alone at the station while every other more experienced fireman rushed to the scene. Gideon also captured additional scenes at and around the firehouse throughout the rest of the day. The documentary includes extensive footage of the subsequent search and rescue mission at Ground Zero and numerous interviews with individual firefighters reflecting on their experiences. Throughout, it maintains the narrative structure that the Naudets first envisioned — a coming of age story about a good-hearted firefighter-but, of course, Tony's experiences took on a far more symbolic and historic significance.

The film first aired on CBS in 2002 to general acclaim from journalists and critics. $^{29}$ But some academics take issue with it. They question, for example, the Naudets' filming and editing decision not to include any of the truly gruesome scenes (most notably Twin Tower workers burning alive and jumping to their deaths after the initial plane crash) that Jules Naudet witnessed but chose not to record. American studies professor Alasdair Spark contends that this move politicizes the film because failing to show such images erases from historical memory the way the United States

\footnotetext{
${ }^{28}$ This was a project in keeping with the aims of their only previous film, Hope, Gloves, and Redemption (1999), which documented the efforts of young Spanish Harlem amateur boxers looking for a way out of dead-end lives.
}

\footnotetext{
${ }^{29}$ The only debates in the mainstream press regarding $9 / 11$ were whether it was too soon to show such raw images from that day and if the FCC was justified in waiving its profanity laws so that the film could air uncensored. Wheeler Dixon, "Introduction," in Film and Television After 9/11, ed. Wheeler Dixon (Carbondale, $\mathrm{L}:$ Southern Illinois University Press, 2004), 10.
} 
failed to protect its citizens..$^{30}$ Similarly, StefCraps, another American studies scholar, takes the film to task for its unspoken ideology:

The filmmakers attempt to mitigate the traumatic potential of their unique atrocity footage by sanitizing it and integrating it into a Hollywood-style coming-of-age drama tracing a probationary fire-fighter's perilous journey from innocence to experience. Thus, the focus shifts from a disorienting and overwhelming sense of loss to comforting, ideologically charged notions of heroism and community that perpetuate an idealized national self-image and come to function as a moral justification for retaliation. ${ }^{31}$

In Craps' view the film entirely removes the terrorist attacks from the global political context that helps explain why the United States generally and the Twin Towers specifically became a terrorist target. He believes that it thus gives credence and support to U.S. policies and military actions in the wake of $9 / 11 .{ }^{32}$ As a scholar, I agree that $9 / 11$ reinforces certain normative nationalist ideals. ${ }^{33}$ As a feminist, I am also disturbed by the Naudets' unquestioningly honorific portrayal not just of the individual firefighters but also of the NYFD itself, an institution plagued by sexism and racism. ${ }^{34}$ But the storyline that the Naudets impose upon the events of September 11, as well as other editorial decisions, could actually make the film more effective in the survey

\footnotetext{
${ }^{30}$ Alasdair Spark, "9/11 and After: Networked Images and Asymmetric Power," in Transitions: Race, Culture, and the Dynamics of Change, ed. Hanna Wallinger (New Brunswick: Transaction Publishers, 2006), 56; Alasdair Spark, "9/11 Multiplied by 24/7: Some Reflections on the Teaching of September 11, , in Issues in Americanisation and Culture, ed. Neil Campbell, Jude Davies, and George McKay (Edinburgh: Edinburgh University Press, 2004), 233.
}

${ }^{31}$ Stef Craps, "Conjuring Trauma: The Naudet Brothers' 9/11 Documentary," Canadian Review of American Studies 37 (2007), 188.

${ }^{32}$ Ibid., 194.

${ }^{33}$ Some of my students' response papers showed that the film did this. For example, one student wrote that the film was important to see because "this is why we fight the war on terror." Another stated "it's the reason why our country went to war," and another asserted that film demonstrated that "America does not back down [because] we are a strong country with a lot of power and will do every action it takes to keep it that way." On the other hand, another student commented that the film showed how the events of September 11 led to "a long, costly war which has crippled our nation and is partially responsible for our current economic depression." And another noted that "We are currently in a war because of this attack on our country and it has since then torn our country apart due to how controversial it is."

${ }^{34}$ Craps, "Conjuring Trauma," 196. 
course by helping students perceive $9 / 11$ first and foremost as a terrorist attack rather than a government conspiracy.

I have used 9/11 in sixteen sections of SUNY Plattsburgh's U.S. history survey course "U.S. Civilization Since 1877" since 2005. We always have a short discussion about general responses to the film directly after viewing it, and most students also choose to write a film response paper on $9 / 11$. In course evaluations, students consistently rated $9 / 11$ the "best film we watched this semester." A typical comment stated that the film "was the most powerful one we watched in class." Unless I prompt them with pointed questions, they never appear to recognize any of the deliberate cinematic moves on the part of the documentarians. ${ }^{35}$ I did not employ $9 / 11$ to directly confront, in any specific, stated way, in either class discussion or writing assignments, the problem of $9 / 11$ conspiracism. When I first began using the film, I was not really aware of such conspiracy theories. Even after they came to my attention, I did not feel able to open up the class for any extensive discussion of September 11 conspiracies, for the reasons noted above: time, large class size, and the realization that simply telling students "those ideas are ridiculous" is not a well-considered pedagogical strategy. In addition, I share with most of my colleagues a deep reluctance to even acknowledge the idea of a secret American government conspiracy to murder its own citizens with airplanes.

In 2011 and 2012, when I introduced the film to students, I did state in passing that I found the idea of such a conspiracy offensive, but I did not poll students about their own exposure to 9/11 conspiracism and they did not raise it themselves in later discussions of the film - maybe because they knew my own position on the matter. Also, over ninety percent of our student body is native New Yorkers, with a significant number coming from New York City and surrounding suburbs, more from other small rural upstate communities. ${ }^{36}$ Their geographical locale in New York might give them some natural immunity against 9/11 conspiracy, since many of them have real life ties to the city. Perhaps this has given them a stronger sense of the reality of those events,

\footnotetext{
${ }^{35}$ Interestingly, in both discussions and evaluations, no student questioned whether the film is a fake, which is how "truthers" respond to $9 / 11$. There are a number of possible reasons for this: The students who are truly convinced by the conspiracy meme might not believe it worth their while to question their history professor-a suspect arbiter of "official" knowledge; $9 / 11$ conspiracism is not as prevalent among my New York state students as studies suggest it is among the iGen overall; or my survey-level students have not yet encountered to any discernable degree $9 / 11$ conspiracy theories. Once or twice students have criticized my use of the film, saying it is "too emotional" or "too close" to events. While these students are picking up on the cinematically manipulative elements of the film, their comments suggest that they view the film as a real depiction of real events, not a faked document that is part of a titillating government conspiracy.
}

${ }^{36}$ See SUNY Plattsburgh, Admissions, "Freshman Class Profile," http://www.plattsburgh.edu/ admissions/freshmen/classprofile.php (accessed June 15, 2014). 
and thus stronger resistance to the appeal of $9 / 11$ conspiracism, than students in other parts of the country might have.

These limitations of my own classroom experience notwithstanding, I believe that student comments in my class discussions, written assignments, and course evaluations suggest that the film could help mitigate students' future reactions to the $9 / 11$ conspiracy meme. To begin with, the film ably communicates the overwhelming confusion, fear, and chaos of the day's events without gory images that might very well shock or horrify students to the extent of shutting down their ability to absorb the film. Despite most students' exposure to incredibly violent films and video games, we should not overestimate students' ability to watch recorded real-life violence without becoming overwhelmed or even traumatized themselves. ${ }^{37}$ Students regularly raise this point in discussion of the film, repeatedly saying that they appreciate the fact that the film did not include images of people falling from the Towers or footage of victims on fire. One student wrote in her film response paper, "I was thankful he did not directly film anybody dying. In doing so, I believe he respected the victims and their families." Because quite a few of my students have personal connections to New York City, the fact that the film does not include such images-which at best would offend them and at worst traumatize them-makes $9 / 11$ a viable teaching tool.

As literary scholar Anneke Smelik points out in an essay on spectatorship and September 11, because trauma is "an overwhelming event that cannot be assimilated and defies comprehension," a human response is to distance ourselves from the event: "When events reach a certain magnitude we naturally doubt their existence." For this reason, she asserts that "just as a disaster is an excess of reality for those involved, the images of the disaster are similarly an excess of reality for the television viewer." Smelik summarizes how $9 / 11$ mediates and contains such images: "The Naudet brothers tried to mitigate the traumatic impact of their unique footage by integrating it with the image of a young fireman in training, in typical Hollywood narrative style." ${ }^{.38}$ Arguing against Craps' criticism of 9/11, Smelik asserts that the "Hollywood narrative" is actually a useful means of portraying September 11:

While I agree with Craps that the documentary filmmakers have tried to make the trauma of September 11 more palatable for the viewer by framing it within the cultural codes of American cinema and television, I disagree with his rather harsh critique that such a "hollywoodization" is necessarily harmful due to its ideological subterfuge. The documentary

\footnotetext{
${ }^{37}$ See Beverly B. Ray, "Voices from the Classroom: Secondary Teachers' Media Use on 9/11," International Journal of Instructional Media 36 (2009), 303-312.

${ }^{38}$ Anneke Smelik, "Mediating Memories: The Ethics of Post-911 Spectatorship," Arcadia: International Journal of Literary Studies 45 (2011), 312, 313.
} 
9/11 makes the trauma into a "comprehensible story," which is exactly what the specialists say should happen with a trauma. The images thus become a performance of memory, of something we have seen before and can thus comprehend better. ${ }^{39}$

The comprehensible story directly counteracts our human desire to doubt the reality of traumatic events, in this case the brutal reality of a major terrorist attack on civilians.

I think that this is a necessary step that $9 / 11$ can help students take so that they might leave class more skeptical about $9 / 11$ conspiracy theories. At their root, conspiracy theories reassure people that what everyone else thinks happened did not in fact really happen. Conspiracy theories impose their own story line on traumatic events; they offer a story that removes adherents from the reality of overwhelming events. But by "framing it within the cultural codes of American cinema and television," $9 / 11$ gives students a way to absorb and comprehend the fundamental reality of September 11. Paradoxically, the filmmakers' efforts to impose cinematically satisfying redemptive meaning on these events might well actually increase iGen students' ability to see the reality of September 11 as a senseless attack that accomplished its goal of destruction and terror.

$9 / 11$ offers a wealth of compelling footage that vividly conveys the chaos and fear of that day -in other words, the reality of Ground Zero. As the reviewer for the New York Times noted, the long minutes of entire darkness as Jules Naudet and the firefighters he accompanied struggled through an impenetrable cloud of dust and debris within Tower One puts the viewer in the reality of that fearful moment:

It feels like you're being buried alive. You're on the ground, gray ash falling everywhere, as if it were being shoveled over you, and you can hear debris rattling on a car overhead, dropping like hail. From the perspective of Jules Naudet's camera, you have run on the street after escaping from the lobby of Tower 1 of the World Trade Center just six or eight minutes before it would collapse. When it does, you are pushed to the ground, and soon everything goes dark. ${ }^{40}$

Even within the broader "Hollywood" narrative constructed by the Naudets' film, scenes like this effectively document what it was like to live through the terrorist attacks in New York City on September 11, 2001. In fact, because these scenes are incorporated into a more familiar story that our practiced media consumer students will recognize, the shocking and unimaginable destruction could be absorbed better.

\footnotetext{
${ }^{39}$ Tbid., 313.
}

${ }^{40}$ Caryn Jams, "Experiencing the Cataclysm, From the Inside," New York Times, March 6, 2002, 1. 
Smelik writes that "The camera not only registers the events from within, literally catching the dust and debris on its lens, but also captures the bewilderment, disbelief, fear, and powerlessness of the people caught in the midst of the disaster." ${ }^{.41}$ In particular, the film documents the firefighters' bewilderment as they struggle to understand the magnitude of what is happening right before their eyes. Even though the narrative arc of the documentary as a whole emphasizes the firefighters' bravery and their organized efforts in the following days to respond to the disaster, there are also numerous shots of firemen on September 11, stunned into immobility. A reviewer in Variety rightly pointed out that "The camera captures the firefighters milling around unsure of their next move; $9 / 11$ shows no heroic deeds. ${ }^{.42}$ More than any other aspect of this film, my students demonstrate that $9 / 11$ effectively reveals the destruction and confusion of that day, even on the part of the firefighters. Some typical written responses include these sorts of comments:

"Everyone in the street was panicking and did not know what to do ... Seeing these reactions from different people gave me the chills because it is very scary to see that happen first hand."

"All you could see were people running all over the place, some just stood there in total shock, not realizing what had just occurred."

"The widespread fear and panic amongst every face that was captured truly helps us understand how traumatic and serious the situation was ... Not even the firefighters, whose job it is to provide reassurance and safety, knew what to do."

"The FDNY didn't exactly know what was going on that day and they didn't know the whole magnitude of destruction when they arrived on the scene. I never knew that there was so much confusion among the first responders...."

Similarly, when asked to identify a new piece of information about the past that they learned from the film, students frequently wrote things such as "the actual moments of debris and dust;" "how dark and dusty it was and how bad the destruction actually was;" "how shocked the firefighters were;" "how confused and lost many of the firefighters were as they tried to help people." One student astutely summarized: "The

\footnotetext{
${ }^{41}$ Smelik, "Mediating Memories," 313.

${ }^{42}$ Phil Gallo, "9/11," Variety, March 18-24, 2002, 31.
} 
footage from within the building showed the heroics of the firefighters, but it also humanized them."

Even one of the most manipulative moves on the part of the filmmakers could perhaps move students toward the learning objective, that is, a clearer understanding of September 11 as a destructive act of terrorism. 9/11 concludes with a swelling acapella rendition of the ballad "Danny Boy" accompanying photographs (a group of four in each shot) of firemen lost on September 11. The song goes on and on, and the number of the dead grows and grows. It is a clear example of what film scholar Birgit Dawes, in an essay on cinema and 9/11, identifies as a growing trend in documentaries to "increasingly use dramatic techniques of selection, combination, alienation effects, and music. ${ }^{\star 43}$ The Naudets obviously intended this tribute to the fallen to have the final say in their film, leaving viewers with an unambiguous message of heroism and perhaps even justification for U.S. policies of retaliation and aggression.

While not denying these problematic aspects of the film's conclusion, I believe that it can also function to help students contend with the reality of the terrorist attacks and inoculate them against $9 / 11$ conspiracy theories. In its final moments, the film practically commands us to feel grief and loss; it deliberately evokes an emotional response from viewers with images and music - an emotional response that will be familiar to practiced media consumers. In doing so, the film helps makes the events of that day more real to our students by giving September 11 an emotional immediacy that will be more and more difficult to access as September 11 recedes into the past. ${ }^{44}$ For students, $9 / 11$ puts faces on some of the people who were murdered, which is precisely the traumatic, incomprehensible, fundamental truth about September 11 that conspiracy theories hope to mitigate. These final images and music, quite calculatingly used by the filmmakers to evoke an emotional response, also reinforce an essential truth about September 11 specifically and history generally: Tragedy and horror are real, and human existence is fragile, easily extinguished for no rational purpose or reason.

One of the firemen interviewed later for the film states that on September 11 he realized "how evil evil can be." Craps criticizes the filmmakers' decision to let this statement stand uncontested, arguing that "with the premise of U.S. benevolence firmly in place, the film can only present the terrorist attack on the World Trade Center as an act of pure and inexplicable evil." ${ }^{, 45}$ But in fact, maybe iGen students very much need to understand "how evil evil can be." The representation in $9 / 11$ of inexplicable evil

\footnotetext{
${ }^{43}$ Birgit Dawes, "Celluloid Recoveries: Cinematic Transformations of 'Ground Zero,"” Transnational American Memories, ed. Udo Hebel (Berlin: Hubert Co. \& GmBH Co., 2009), 292.
}

\footnotetext{
${ }^{44}$ Every year, more and more students note how young they were on September 11, 2001, and how little they actually remember about that day. As one student summarized, "As you go farther and farther away from this event there will be fewer and fewer people that were alive to remember the catastrophe."
}

${ }^{45}$ Craps, "Conjuring Trauma," 193. 
could be exactly what many of our students need in order to be more skeptical of conspiracy theories. 9/11 conspiracies offer convoluted but engaging and totalizing explanations for what happened that day. Rather than being forced to contend with the difficult truth that we are vulnerable beings in a world that can be ripped asunder easily by a few violent individuals, $9 / 11$ conspiracy adherents can be comforted by the idea that such a horrific event could only happen through deliberate action orchestrated by a huge but somehow hidden network of powerful villains. In marked contrast to conspiracist thinking, the narrative of $9 / 11$, even the calculated final tribute scene, directs viewers to an emotional response not unlike the fireman's realization of "how evil evil can be." And this emotional response might be a necessary one for understanding the reality of terrorism.

Even students who experienced the events in some way directly could use the film to gain such understanding. For example, one student reflected in her film response paper about her anxiety as a third grader on September 11 waiting to hear from her mother, who was working in Manhattan. She concluded that after watching 9/11, "I finally realized what happened, why it happened, and how many lives were lost." Another student used the film response paper to admit the limits of her own knowledge and explain that the film had increased her understanding:

Being the kind of person I am, I like to pretend as if $I$ know all there is to know about things I truly don't know much about. $9 / 11$ was one of those events. In watching this documentary, I learned more about this event than I could have ever through textbooks and articles. This was a first-hand glance, rather, a reality check, as to how quickly disaster grasped ... our country and shook it without remorse.

A "reality check" is precisely what I hope showing $9 / 11$ accomplishes in the survey class. By giving students this dose of reality, in the readily comprehensible framework of a coming of age story, my hope is that when they leave my class and subsequently encounter the $9 / 11$ conspiracy meme, they will be more reluctant to leave that reality behind and indulge in the fantasies of secret government plots.

\section{Conclusion}

At times I am uncomfortable in class when I show 9/11. I always choke up watching the Naudet brothers reunited at the firehouse, after being separated for hours in all the confusion and unsure if the other was even still alive. During the final scene, although it is in some ways the very reaction I have sought to create in students, I am unnerved when I hear some of them sniffling, clearing their throats, and clearly struggling not to cry. I have been reassured about using the film when students who lost acquaintances, friends, and even family members on September 11 have told me personally in class discussion or in written comments that they are glad I showed the 
film. But I do not know if I am doing the right thing. Is this really an ethical way to try to advance student learning? Am I using a savvy teaching strategy that fully acknowledges and contends with iGen's ways of accessing information? Or have I surrendered to the temptation to give them what they expect in their entertainment-a good show, with a highly engaging story line-in order to manipulate an emotional rather than intellectual response? Should I instead push through my own personal reluctance to allot valuable class time to discussing forthrightly conspiracy theories that I find reprehensible? And would it even be possible in a large general education class to do this productively?

Based on my evaluation of their comments and written work, this film appears to advance my students' learning about the events of September 11, and such concrete knowledge is perhaps the best tool I can give survey students to resist the conspiracy meme. Here, as in my class, much of what students learn might not be self-evident or put into practice until weeks, months, or even years later. Have I inoculated students successfully against the $9 / 11$ conspiracy meme? I hope so. Using $9 / 11$ probably won't change the minds of those few students who are completely convinced of a government conspiracy. But it might well combat vague ideas and unformed suspicions among the many students who have "seen something about September 11 online." 9/11 can effectively speak to such students and offer a compelling representation of the chaos and confusion caused by a few individuals determined to terrorize a population. Ideally, it can offer a rejoinder to the conspiracy meme that will assault our students every time they Google "September 11." 